\title{
Interplay Between VLE's Artifacts and Learning Abstractions
}

\author{
Daiana de Freitas Carpenedo, Paulo Silas Souza Severo, Wagner dos Santos Marques, Jaline \\ Gonçalves Mombach, Andréia dos Santos Sachete, Fábio Diniz Rossi \\ Federal Institute of Education, Science and Technology Farroupilha, Brazil
}

\begin{abstract}
Virtual learning environments (VLEs) consist of platforms for maintenance and development of the most diverse courses offered in distance learning modality. These platforms provide the teacher with a set of educational artifacts that allow the mediation and perception of the students' learning. However, many teachers use the artifacts in an arbitrary way regarding the abstractions of learning proposed by genetic epistemology. The use of artifacts in line with this theory can logically link student development. In this way, this article relates each artifact to one of the four proposed abstractions, producing an oracle for the future development of activities.
\end{abstract}

\section{Introduction}

Distance Education (DE) [7] is the globalization of education. This modality consists of offering courses at different levels to places where perhaps a course could never be provided due to various factors such as distance, lack of physical or pedagogical structure. The last years have provided an advance and maturity on the understanding of what is distance education, differentiating the educational processes of this modality of traditional classroom teaching [8], [2].

This breakthrough has boosted the emergence of new technologies aimed at enabling mediation between teachers and students, learning objects focusing on some specific skill or competence, performance management environments, and courses. Overall this technology, the creation of educational materials aimed at distance education has developed as a strand that seeks to aggregate all these technological possibilities, with the aim of enhancing teaching [3], [10].

However, distance education keeps some issues that are inherent to teaching, be it at a distance or not, such as the assessment of student development [18]. The discussion about evaluation in face-to-face courses is always on the agenda and still current, since evaluating learning should not be anything technical [16]. In order to support understanding in the acquisition of knowledge that directly implies education, Jean Piaget classifies in abstractions, as the subject extracts information about the objects it interacts, thus relating each type of interaction to a concept [14].

Probably the artifacts developed in distance education environments have not been created based on a theory of learning. However instead thinking of the purpose of the application in offering ease in explaining or providing interaction about a specific content but now in possession of theory, the teacher can organize the script of his DE class so that learning is a logical path of cognitive development through the available artifacts.

This article proposes to describe the learning abstractions proposed by Piaget, and to classify in each of these, the artifacts available to aid in the teaching and learning processes of Moodle [12], one of the virtual environments most used by distance education institutions. For this, the article discusses the abstractions of Piaget's theory, the artifacts that are maintained by the Moodle distance education environment, and the classification of the artifacts as the learning abstraction that it allows. In the end, we hope that this article will serve as a subsidy to the teacher regarding the use of artifacts in the creation and development of DE classes.

\section{Piaget Abstractions}

The process of human development is a subject often addressed by psychologists and educators. Among the research topics involved in the analysis of problem-solving ability, abstraction, creativity, memory, among other intellectual skills that are improved during the intellectual growth of individuals.

In this context, the Genetic Epistemology [14] is one of the proposals of higher visibility in the contemporaneity. Such a theory is based on elements such as cognitive structures (i.e., physical and mental patterns corresponding to stages of child development) to understand the phases of the process of obtaining knowledge, as well as other factors involved such as individual and joint learning.

According to the theory of Genetic Epistemology, the acquisition of knowledge occurs through interactions between the subject and the object, where cognitive structures, called schemas, store and organize the information that the individual acquires about himself/herself, the environment in which he/she is inserted or purposes. Three processes can manipulate schemes:

- Assimilation: occurs when the subject seeks similarities between the new information obtained (motor, conceptual or conscious) and the existing schemes. 
- Accommodation: represents cases where the person is not able to assimilate the new information with any of the existing schemes. In these circumstances, the person may harbor such information in a new scheme or even extend some of the existing schemes by adding such information.

- Equilibration: refers to the process where the individual analyzes their current state of knowledge and makes changes in their schemas, which allows it to reach a state of greater intellectual balance.

In addition to the schema-related study, Genetic Epistemology also analyzes the different types of abstraction, which are ways in which individuals select and extract information from objects. According to this theory, there are four types of abstraction: i) empirical abstraction, ii) reflective abstraction; iii) reflective abstraction, and iv) pseudoempirical abstraction.

Empirical abstraction occurs through external experiences obtained by the subject. In this type of abstraction, the individual can extract information from the characteristics of the objects (for example, an individual can analyze characteristics such as the color or the weight of a box) or also of stock properties (for example, force and velocity of a kick).

In this type of information extraction, the subject needs to focus on a single characteristic of the object so that it can abstract information about it. For example, when analyzing the attributes of weight, color, and texture of a box empirically, the individual needs to focus on one feature at a time, temporarily ignoring the others [9].

In empirical abstraction, information is extracted through actions of the subject concerning the object or action. For example, the subject can illuminate an object to observe its color. In this case, the person exerts an effect on the object (the act of enlightening). In this way, the perception obtained on a specific characteristic of an object is a result of the conditions in which both the subject and the object are at that moment, which allows individuals to arrive at different conclusions regarding a particular characteristic of the same object [5].

Reflective abstractions represent the construction of logical-mathematical structures carried out by the individual during his cognitive development. Unlike empirical abstraction, where information is extracted from the external environment (of objects or actions), the source of reflective abstraction is internal. Hence, such abstractions cannot be observed, whereas they occur in the mind of the subject, but can be deduced through their behavior.

This type of abstraction concerns the coordination of the actions or operations carried out by the individual, where he develops a course of action based on his knowledge. For example, a student who learned the concepts of addition and multiplication will realize that adding a given number $\mathrm{n}$ times will have the same result as multiplying that number by $n$. That is, the student will be coordinating the two sum actions in a multiplication action [5].

The process of reflexive abstraction can be divided into two phases: projection and reflection. In the first phase, the subject's cognitive activities (i.e., schemas, cognitive structures, coordination of actions, operations, etc.) are elevated to a higher mental level. At this stage, specific characteristics of these cognitive activities are selected to be used for purposes other than those initially intended for them. The reflection phase is responsible for reorganizing the cognitive activities that have been moved to the new mental level, establishing relationships between these activities and those already existing at this new level.

Pseudo-empirical abstractions are a variation of the reflective abstractions that occur when the subject coordinates specific actions that need to be performed externally for the expected result to be achieved. This type of abstraction involves elements of reflective abstractions (coordination of activities) and empirical (actions execution) abstractions. An example of pseudo-empirical abstraction occurs when a child who, even though he has already learned the concept of subtraction, needs to manipulate some object (e.g., subtraction with fingers, note down on paper, etc.) to perform a calculation [17].

By being performed internally (i.e., in the subject's mind), reflective abstractions may occur consciously or unconsciously. Coordination's, where the subject has a consciousness about being abstracted, are called reflected abstractions [19]. As the individual's cognitive level increases, the number of pseudoempirical abstractions decreases, while the number of reflected abstractions increases, that is, the individual can perform a higher number of actions without the help of external objects [11].

In the scope of distance education, several studies have been undertaken to aim at adapting content in virtual learning environments according to the students' need. In this way, it is relevant that teachers know what the functionalities available in these systems are so that they can use the full potential of these educational resources.

\section{Moodle Artifacts}

Moodle (Modular Object-Oriented Distance education [12] is a learning platform that has been developed to assist educators and students during the learning process. The platform consists of artifacts that make it possible to use both fully online courses and in presence or semi-presence courses. Moodle is provided free of charge as Open Source software, which allows interested educational institutions and 
users to use, modify and distribute the system according to their needs [4].

Moodle is based on social constructionism, which emphasizes the cognitive concept of learning based on experience rather than knowledge transmitted through traditional methods of teaching such as books and lectures. Thus, its artifacts are developed based on this concept. In the teaching and learning activities, educators and students have the same level of importance, while there is the mutual exchange of knowledge, which are acquired and built based on the experiences of those involved [20].

Table 1. Types of Moodle platform artifacts.

\begin{tabular}{|l|l|}
\hline Type & \multicolumn{1}{|c|}{ Artifact } \\
\hline & $\begin{array}{l}\text { Evaluation surveys, Chat, } \\
\text { Forum, Glossary, Activities, } \\
\text { Questionnaires, Diary, Lesson, } \\
\text { and Wiki }\end{array}$ \\
\hline Activities & $\begin{array}{l}\text { Opinion search, File } \\
\text { Directory, Organization Labels, } \\
\text { Fesources }\end{array}$ \\
File, URL, Books, and Web \\
\hline
\end{tabular}

Furthermore, the system can be installed on any platform with PHP (Hypertext Preprocessor) support, which is a technology used in the development of software. Also, such technology has an Open Source license and can be installed at no additional cost. The installation process is considered simple, and after the process, an account with higher privileges is provided to the system administrator. Therefore, due to the characteristics of free software, the administrator can have full access to the source code and can make modifications according to their needs.

Many traditional network learning resources are made available on the platform, and because the course software package is available via the Internet, the functionalities of virtual learning environments (VLEs) are also provided. VLE provides structures that enable the manipulation of educational materials in virtual environments [13]. Moodle artifacts can be divided into activities and resources, as shown in Table 1.

VLE resources enable and facilitate interaction between students and teachers. After installing and configuring, they present a number of features that allow teachers to create and share learning materials with students so that they can overcome possible limitations of traditional teaching and improve the learning effectiveness of their students. Moodle's multifunctional modules, resources, and activities can guarantee the useful accomplishment of personalized education:

- Evaluation surveys: Evaluation surveys are used to collect student data. It is possible to elaborate questions with different options, and thus measure the opinions of those involved and then make decisions according to the majority. It is a viable alternative for quick polls and voting.

- Dialogue: Dialogue makes communication simple among participants enrolled in the same course. The teacher can open dialog calls with the student, just as the student can send messages to the teacher. There may also be a dialogue between two students.

- Chat: Allows communication between students and teachers. It can be an excellent tool for clarifying doubts and other purposes. Chat sessions can be scheduled, include profile images, accept sending URLs, graphic symbols, embedded HTML and multimedia content.

- Diaries: Diaries activity allows students to annotate and comment on specific content. In this tool, all comments made will be restricted to the user who performed it.

- Lesson: Lets you create and manage a set of related pages. Each of these pages contains questions interspersed with a classification that condition the student's progress to the next pages according to their answers.

- Forum: Forums are discussion tools and can be used to address doubts and even as a space for reflection on the subject matter. Forums can be intended for teachers, news and general use.

- Glossary: This resource allows, with the collaboration of those involved, to create a dictionary with the terms considered relevant concerning specific contents. Subsequently, the terms can be searched and viewed by all students.

- Activities: This feature allows teachers to assign tasks to students. The activities can have a time limit of sending and enables the sending of files and files in general, as well as send textual responses through the appropriate text fields and made available by the platform.

- Questionnaire: This is a Moodle activity, which enables users to develop numerous types of evaluation questionnaires or student support. Also, the questionnaires may have limited availability time and may present the questions at random.

- Wiki: Makes it possible to create and develop content and group documents. Therefore, the collaboration among those involved is emphasized, and teamwork emerges. This activity allows access to the 
various versions of the documents and thus verify the changes made by the collaborators.

- Opinion research: In this functionality, it is possible to obtain a statistical survey on a specific subject or content. Several components are available in the data collection, and similar to the

- questionnaires may also have availability timeout.

- File directory: You can insert and make available various types of files and contents in the course created, such as simple texts, files with images, videos, and PDFs. It also allows creating pages with HTML extension, through an editor built into the system.

- Organization Labels: It will enable the insertion of labels in the activities and contents made available in the discipline. Labels can be text and even multimedia content (e.g., Videos, Audios). It is used for description or also to separate types of content, in order to facilitate the understanding of the student concerning the subject in question.

- Files: It is possible to persist and make available several file extensions, such as texts (e.g. "txt," "odt," "pdf") and multimedia content such as videos and audios.

- URL: In order to provide additional content to students in order to complement activities and content covered in the course, it is possible to add URLs, i.e., web page addresses, which contain supplementary materials.

- Books: Resource that enables the creation of a digital book on the platform. Several options are available during authorings, such as chapter insertion, multimedia content, and text formatting.

- Web Pages: For creating more elaborate content, it is possible to create web pages within the platform. The creation is done through the insertion of HTML codes, and allows the presentation of more elaborate contents, being possible a more advanced manipulation of images, videos, tables, lists, texts, and other contents.
All of the tools mentioned give teachers many advantages in the search for teaching alternatives. Besides, the application has been translated into more than 78 languages and allows great visual customization and can be adapted according to the institution in question.

However, Moodle adopts the SCORM (Sharable Content Object Reference Model) [1] standard, which is a template of technical specifications that provides a set of norms and rules that aim to standardize elearning contents. The rules define rules of interoperability, accessibility, and reuse. Content is divided into SCOs (Sharable Content Objects), which are the smallest unit of information that can be managed by Academic Management System (SGAs).

Furthermore, SCOs are interoperable and modular, and they can be treated individually and inserted in different platforms. The interoperability of these objects results from the packaging and execution specifications in SCORM. Each packet created must have an XML file with metadata, which communicates the SCO with the educational tool. Information such as material name, description, and the course can be entered in this manifest file. Therefore, with the use of SCORM, it is possible to import content from other platforms and e-learning systems already produced [21].

\section{Classification}

Since some types of abstraction are more commonly used in performing certain activities, the categorization of educational activities according to the types of abstraction may allow teachers to choose the activities most recommended for their students.

Thus, Tables 2 present Moodle functionalities categorized according to the types of abstraction presented in the Genetic Epistemology theory. Also, some of the features have been classified into more than one type of abstraction because they can be used in different ways. The URL resources, Organization Labels, and File Directory are not directly employed by students, whereas they are integrated with other Moodle resources or activities. For example, the URL feature can be used in Wikis, Chats or Forums. Therefore, these resources have not been categorized.

Such relationships between Moodle artifacts and abstractions of Genetic Epistemology may enable the development of more effective lesson plans, while teachers who have access to such activities and resources can choose which of these most effectively meet the needs of their students. 
Table 2. Artifacts classification and description of application

\begin{tabular}{|c|c|c|}
\hline Abstraction & Artifact & Description \\
\hline \multirow[t]{4}{*}{ Empirical } & Glossary & $\begin{array}{l}\text { The Glossary allows students to describe terms related to a particular } \\
\text { topic. During the search for terms, students can consult books, } \\
\text { dictionaries or even the Internet, and can obtain different points of } \\
\text { view, which classifies such activity as an empirical abstraction. }\end{array}$ \\
\hline & Wiki & $\begin{array}{l}\text { While using Wikis, students can acquire new information by } \\
\text { analyzing content added by their contributors. For example, a } \\
\text { student can examine the colors present in a specific image attached } \\
\text { to the document (empirical abstraction). }\end{array}$ \\
\hline & Web pages and Files & $\begin{array}{l}\text { According to the content added by the teachers in the web pages and } \\
\text { the archives, students should make use of the empirical abstraction } \\
\text { in order to reach the objective of these activities. For example, a } \\
\text { student may observe the contrast between existing colors on a web } \\
\text { page or in an image file. }\end{array}$ \\
\hline & Books & $\begin{array}{l}\text { In the Books feature, students make use of empirical abstraction by } \\
\text { exerting an action on the object (reading act) in order to obtain } \\
\text { information about the object. Also, the point of view acquired may } \\
\text { vary from student to student, depending on the content presented in } \\
\text { the book. }\end{array}$ \\
\hline \multirow{5}{*}{ Reflective } & Dialogue & $\begin{array}{l}\text { During the dialogue, the student exchanges information with the } \\
\text { interlocutor, forming or expanding his/her cognitive schemas in an } \\
\text { uncontrolled way, which characterizes reflective abstraction. }\end{array}$ \\
\hline & Chat & $\begin{array}{l}\text { Similar to the dialogue, the student can exchange experiences during } \\
\text { the conversation with the interlocutors, acquiring new information } \\
\text { or reinforcing existing concepts in their cognitive schemas }\end{array}$ \\
\hline & Lesson & $\begin{array}{l}\text { This resource causes the subject to elevate his/her cognitive } \\
\text { activities to a new mental level, where the previously obtained } \\
\text { knowledge forms a new cognitive scheme responsible for solving } \\
\text { the problem proposed in the lesson. For example, a student reads } \\
\text { about a specific mathematical concept and some cases of its } \\
\text { application, and during the lesson applies that concept to other } \\
\text { purposes. }\end{array}$ \\
\hline & Forum & $\begin{array}{l}\text { The Forum, similar to Chat, allows users to exchange knowledge } \\
\text { while discussing a particular subject. During such interaction, } \\
\text { individuals' cognitive structures are adapting as new information is } \\
\text { obtained. }\end{array}$ \\
\hline & Web pages and Files & $\begin{array}{l}\text { Depending on the material inserted by teachers, web pages and files } \\
\text { may require students to make use of reflective abstraction to } \\
\text { assimilate their content. For example, a student can watch a video } \\
\text { (which can be made available through a file or on a web page) that } \\
\text { shows a new way of handling a certain tool. In this interaction, the } \\
\text { student may unconsciously understand that this tool can be used in } \\
\text { the way presented in the video. }\end{array}$ \\
\hline \multirow[t]{4}{*}{ Pseudo-Empirical } & $\begin{array}{l}\text { Evaluation surveys, } \\
\text { Questionnaire, and Opinion } \\
\text { research }\end{array}$ & $\begin{array}{l}\text { Such functionalities require the subject to reflect on the knowledge } \\
\text { previously obtained, making connections between their cognitive } \\
\text { schemas, in order to formulate their point of view concerning the } \\
\text { themes addressed in the questions. For example, in an opinion } \\
\text { survey on the effectiveness of collaboration, while developing } \\
\text { online mind maps, a student may remember their experiences, } \\
\text { judging them positively or negatively, to formulate their opinion on } \\
\text { the subject. }\end{array}$ \\
\hline & Wiki & $\begin{array}{l}\text { While using wikis, students can organize the content of their } \\
\text { cognitive schemas in order to add relevant information to the } \\
\text { document being written (Pseudo-Empirical Abstraction). }\end{array}$ \\
\hline & Activities & $\begin{array}{l}\text { The activities allow the student to reflect on the contents previously } \\
\text { discussed, establishing links between their schemes, in order to } \\
\text { solve the proposed challenge. For example, to perform an activity, } \\
\text { the student can research the pros and cons of a tool to achieve a } \\
\text { specific task. }\end{array}$ \\
\hline & Web pages and Files & $\begin{array}{l}\text { Teachers can also add content and files various content that may } \\
\text { require reflective abstraction from students. For example, teachers } \\
\text { can create web pages containing quizzes. }\end{array}$ \\
\hline
\end{tabular}




\section{Conclusion}

Many of the practices of traditional classroom teaching are adapted to the DE modality. It is a practice that, although it still exists, has lost ground to a new didactic-pedagogical vision that allows a new way of thinking about the availability and arrangement of classes in the DE mode [6], [15].

However, when the DE teacher thinks of using an artifact available in the virtual environment, it is usually considered of as a common activity, that is, it has no purpose in itself, and is used only as a tool for transmitting some information or evaluating a given subject matter. What we have tried to show in this chapter is the ability of the teacher to use DE artifacts as an end-activity, and this means employing the correct artifact for each moment during the discipline.

In order to do so, it was used the abstractions of Genetic Epistemology of Piaget, a very accepted theory, to develop relations with each artifact available in a virtual environment. The relationships were based on Moodle artifacts, virtual environment widely used by educational institutions offering DE courses. However, the artifacts presented here are available in most virtual learning environments.

These relationships are expressed and described, offering support to teachers at the time of creation of virtual classes, and enable the teacher to organize different types of student interaction with the virtual environment so that knowledge is built progressively and continuously.

\section{References}

[1] Advanced Distributed Learning. "SCORM Overview." 2019. Available at: https://www.adlnet.gov/adlresearch/scorm/. Last accessed on: 2019-10-30.

[2] Bates, AW Tony. 2005. "Technology, e-learning and distance education.” Routledge.

[3] Beldarrain, Yoany. 2006. "Distance education trends: Integrating new technologies to foster student interaction and collaboration.” Distance education 27 (2): 139-153.

[4] Di Cerbo, Francesco, Gabriella Dodero, and Giancarlo Succi. 2008. "Extending moodle for collaborative learning." ACM SIGCSE Bulletin40 (3): 324-324.

[5] Dubinsky, Ed. 2002. "Reflective abstraction in advanced mathematical thinking." In Advanced mathematical thinking, 95-126. Springer.

[6] Garcia-Penalvo, Francisco Jose. 2008. Advances in eLearning: experiences and Methodologies: experiences and Methodologies. IGI Global.

[7] Gunawardena, Charlotte Nirmalani, and Marina Stock McIsaac. 2013. "Distance education." In Handbook of research on educational communications and technology, 361-401. Routledge.
[8] Jonassen, David, Mark Davidson, Mauri Collins, John Campbell, and Brenda Bannan Haag. 1995. "Constructivism and computer-mediated communication in distance education." American journal of distance education9 (2): 7-26.

[9] Kamii, Constance, and Linda Leslie Joseph. 2004. Young children continue to reinvent arithmetic -2 nd grade: Implications of Piaget's theory. Teachers College Press.

[10] Keegan, Desmond. 2013.Foundations of distance education. Routledge.

[11] Montangero, Jacques, and Danielle Maurice-Naville. 2013. Piaget or the advance of knowledge: An overview and glossary. Psychology Press.

[12] Moodle. Available at: https://moodle.org/. Last accessed on: 2019-10-30.

[13] OLeary, R, and A Ramsden. 2002. "Virtual learning environments. Learning and Teaching." Support Network Generic Centre/ALT Guides, LTSN.

[14] Piaget, Jean, and Eleanor Duckworth. 1970. "Genetic epistemology.” American Behavioral Scientist13 (3): 459480.

[15] Shee, Daniel Y, and Yi-Shun Wang. 2008. "Multicriteria evaluation of the web-based e-learning system: A methodology based on learner satisfaction and its applications." Computers \& Education 50 (3): 894-905.

[16] Shepard, Lorrie A. 2000. "The role of assessment in a learning culture." Educational researcher29 (7): 4-14.

[17] Steffe, Leslie P, and Paul Cobb. 2012. Construction of arithmetical meanings and strategies. Springer Science \& Business Media.

[18] Stella, Antony, and Arumugham Gnanam. 2004. "Quality assurance in distance education: The challenges to be addressed." Higher education 47 (2): 143-160.

[19] Von Glasersfeld, Ernst. 1991. "Abstraction, representation, and reflection: An interpretationof experience and Piagets approach." In Epistemological foundations of mathematical experience, 45-67. Springer.

[20] Xiaoqiong, Yang, Yang Guoqing, and Zheng Zeng. 2013. "Personalized teaching model based on Moodle platform." In Proceedings of the International Conference on Information Engineering and Applications (IEA) 2012, 27-35. Springer.

[21] Yang, Rui, and WenJie Fan. 2015. "Design and implementation of Adaptive Content Trisection System based on SCORM." In First International Conference on Information Sciences, Machinery, Materials and Energy, Atlantis Press. 